\title{
Epidemiology of clinical congenital and neonatal malaria in endemic settings: a systematic review and meta-analysis
}

\author{
Celestin Danwang ${ }^{1 *}\left(\mathbb{D}\right.$, Jean Joel Bigna ${ }^{2}$, Rolf Nyah Tuku Nzalie ${ }^{3}$ and Annie Robert ${ }^{1}$
}

\begin{abstract}
Background: In order to attain the objectives set out in the global technical strategy against malaria 2016-2030, it is important to have accurate epidemiological data on malaria in all age categories, including those which are often neglected because of an apparent low burden of disease. The current systematic review with meta-analysis synthesizes the epidemiology of clinical congenital and neonatal malaria in endemic areas.

Methods: PubMed, EMBASE, Global Index Medicus, and Web of Science were searched up to 30th October 2019, to identify observational studies reporting on congenital (0-7 days) and neonatal (0-28 days) malaria. No restriction related to language was applied. Study selection, data extraction, and methodological quality assessment were performed independently by two investigators. A random-effects meta-analysis was used to pool prevalence data. Prevalence were adjusted taking into account the variance due to diagnostic method and regional distribution. Subgroup analyses were performed to identify sources of heterogeneity in case of substantial heterogeneity. This review was registered in PROSPERO with number CRD42020150124.

Results: The bibliographical search identified 1,961 studies, of which 22 were finally retained with a total population of 28,083 neonates. The overall crude prevalence of clinical congenital malaria was $40.4 \%$ ( $95 \% \mathrm{Cl} 19.6-67.7 ; 17$ studies). The adjusted prevalence considering the variance due to difference in region/country (hierarchical model) was $33.7 \%$ o $(95 \% \mathrm{Cl} 6.9-77.2)$. There was no difference between the prevalence of clinical congenital malaria in Africa $39.5 \%$ ( $95 \% \mathrm{Cl} 17.2-59.5 ; 15$ studies) and outside Africa $56.3 \%$ (95\% Cl 0.0-406.1), $p=0.867$. The overall crude prevalence of clinical neonatal malaria was $12.0 \%$ ( $95 \% \mathrm{Cl} 1.4-30.3 ; 12$ studies), and the adjusted one (considering the variance due to diagnostic method and the region/country) was $12.9 \%$ o $(95 \% \mathrm{Cl} 0.1-39.7)$. There was no difference between the prevalence of clinical neonatal malaria in Africa $12.1 \% 0(95 \% \mathrm{Cl} 1.3-31.2 ; 11$ studies) and outside Africa $12.5 \%$ o (95\%Cl 0.0-52.9), $p=0.802$.
\end{abstract}

Conclusion: This study suggests a high prevalence of clinical congenital and neonatal malaria. It calls for an intensification of preventive measures against malaria during pregnancy and in the neonatal period, and to consider neonates as a distinct age category in the elaboration of malaria treatment and prevention guidelines.

Keywords: Epidemiology, Malaria, Neonates, Review

\footnotetext{
*Correspondence: danram07@yahoo.fr

1 Epidemiology and Biostatistics Unit, Institut de Recherche

Expérimentale et Clinique, Université catholique de Louvain, Brussels, Belgium

Full list of author information is available at the end of the article
}

\begin{abstract}
Background
During the past decade, considerable efforts have been made to reduce the global burden of malaria [1-3]. These efforts have led to significant reductions in malariarelated morbidity and mortality [1-5]. Indeed, the World Health Organization (WHO) has estimated that
\end{abstract}

(c) The Author(s) 2020. This article is licensed under a Creative Commons Attribution 4.0 International License, which permits use, sharing, adaptation, distribution and reproduction in any medium or format, as long as you give appropriate credit to the original author(s) and the source, provide a link to the Creative Commons licence, and indicate if changes were made. The images or other third party material in this article are included in the article's Creative Commons licence, unless indicated otherwise in a credit line to the material. If material is not included in the article's Creative Commons licence and your intended use is not permitted by statutory regulation or exceeds the permitted use, you will need to obtain permission directly from the copyright holder. To view a copy of this licence, visit http://creativeco mmons.org/licenses/by/4.0/. The Creative Commons Public Domain Dedication waiver (http://creativecommons.org/publicdomain/ zero/1.0/) applies to the data made available in this article, unless otherwise stated in a credit line to the data. 
the incidence of malaria has been reduced by $22 \%$ over the last 8 years in sub-Saharan Africa, while the figure is close to $70 \%$ in South-East Asia [1].

Although in some continents, several countries have eradicated malaria as endemic infectious disease in the last 50 years, other countries still remain endemic to malaria with varying trends over time, especially in subSaharan Africa [6-11]. Indeed, in 2018, 19 sub-Saharan African countries and India bore $85 \%$ of the world's malaria burden, with $94 \%$ of malaria-related death occurring in sub-Saharan Africa [1]. These data point out difficulties in achieving the global technical strategy against malaria 2016-2030, which aims to reduce malaria morbidity by at least $40 \%$ in 2020 [1] This calls for intensified efforts, particularly in the regions of the world most affected by malaria.

Assessment of the level of achievement of malaria control and eradication goals has been possible in recent years thanks to the presence of high-quality global data. Enabling the assessment of the global burden of malaria often at very high spatial resolutions $[2,4,5]$. Nevertheless, among all published studies reporting on malaria, many focus on adults, pregnant women and children under 5 years of age $[4,5,12]$. Yet this last age category includes several heterogeneous groups with different immunological characteristics and varying susceptibility to infection [13-15].

While it is recognized that pregnant women and children under 5 years of age are the two categories of the population most vulnerable to malaria, data for children under 5 years of age need to be disaggregated because they include subgroups (neonates, infants, toddlers and early childhood children) that have different immunological characteristics and host-parasite interactions [13-18].

Currently, in countries with high malaria endemicity, the diagnosis of malaria in neonatal period is considered as a differential diagnosis of numerous other infections. It is only mentioned when an infectious work-up has formally ruled out any other aetiology of sepsis in a neonate $[19,20]$. However, given the resurgence of observational studies reporting the presence of asexual forms of Plasmodium in neonates of mothers infected with malaria on one hand, and of studies reporting malaria as the sole aetiology of neonatal infection in symptomatic infants on the other hand, congenital and neonatal malaria has received renewed interest from healthcare workers in recent years [20-25]. Therefore, to curb the burden of malaria globally with specific attention in endemic areas, it is important to accurately analyse epidemiological data with the aim of informing policy makers, and hence produce tailored public health interventions. The present systematic review with meta-analysis aims to provide a comprehensive overview of clinical malaria occurrence in neonates in endemic settings.

\section{Methods}

This review was registered in the Prospective International Register of Systematic Reviews (PROSPERO with number CRD42020150124) and is reported according to the MOOSE (Meta-analysis Of Observational Studies in Epidemiology) guidelines [26].

\section{Search strategy and selection criteria}

The following databases were searched up to October 30th, 2019: PubMed, EMBASE, Global Index Medicus, and Web of Science (Web of Science Core Collection, Current Contents Connect, KCI-Korean Journal Database, SciELO Citation Index, Russian Science Citation Index) to identify observational studies reporting on neonatal and congenial malaria with at least 30 participants. No restriction related to language was applied. The search strategy was designed for EMBASE and was modified to suit other databases (Additional file 1: Table 1). It was based on a combination of medical subject heading terms and text words related to congenital and neonatal malaria. The references of the retrieved articles were also screened with the aim to identify other potential data sources. Letters, commentaries, reviews, and editorials, as well as studies from which it was not possible to extract data on the prevalence of congenital and neonatal malaria were excluded.

\section{Malaria cases definition}

Several definitions of neonatal and congenital malaria are used in the literature, but none has been consensually adopted [15, 27-29]. In this review we have considered neonatal malaria as: the presence of a positive parasitaemia with asexual forms of plasmodium associated with at least one symptom (fever, jaundice, anaemia, splenomegaly, vomiting, hepatomegaly, diarrhoea, restlessness, drowsiness, convulsions, poor feeding, cyanosis, pallor, respiratory distress) in a child less than or equal to 28 days [29, 30]. When it occurred in a neonate up to 7 days, it was considered as congenital malaria [27, 29]. Cases of incidental parasitemia, i.e. malaria-positive parasitaemia in asymptomatic neonates were not considered as neonatal or congenital malaria.

\section{Data extraction and management}

Two investigators (CD and RNN) independently screened the titles and abstracts of the references found through the bibliographic search. Subsequently, the full texts of retained articles were uploaded and scrutinized for final inclusion. When the two investigators did not 
agree on the inclusion of an article, a discussion was held to reach a consensus.

With the help of a ready-made electronic data extraction sheet, two of the investigators (CD and RNN) independently extracted from the full texts, information in accordance with the objectives of the review. A third author then proceeded to cross-check and synthesize the extracted data. Data of interest included: surname of the first author, year of publication, country where the study was conducted, study design, sampling method, timing of data collection, proportion of males, specific characteristics of the study population, proportion of pregnant women who took intermittent preventive treatment for malaria, sample size and number of cases of clinical neonatal and/or congenital malaria.

To assess the methodological quality of each study, two investigators (CD and RNN) used an adapted version of the Joanna Briggs Institute tool for prevalence data [31].

\section{Data synthesis and analysis}

The analyses were performed using the packages 'metafor', 'meta', and 'dmetar' within the statistical software $\mathrm{R}$ (version 3.6.2). A DerSimonian and Laird randomeffects model for meta-analysis was used to obtain the pooled prevalence. Prior to that, the variance of individual studies was stabilized with the Freeman-Tukey double arc-sine transformation [32]. Prevalence per 1,000 neonates $(\%)$ were reported with their $95 \%$ confidence intervals. Cochran's $X^{2}$ and $I^{2}$ tests were used respectively to assess the presence and the amount of heterogeneity [33, 34]. $\mathrm{I}^{2}$ values of $25 \%, 50 \%$ and $75 \%$ were considered as representing low, medium and high heterogeneity respectively. Whenever substantial heterogeneity was found $\left(\mathrm{I}^{2}>50 \%\right)$, a subgroup analysis was performed to determine its possible sources using the following grouping variables: regions (Africa and outside Africa) and malaria diagnostic method used (microscopy, antigen detection, molecular biology). Adjusted prevalence was computed using a multivariate meta-analysis to take into account the variance due to differences in diagnostic methods, and the variance due to region/country, in a hierarchical model. Funnel plot inspection and the Egger test $(p<0.10)$ were used as the two means of detection of publication bias [35]. A $p$ value $<0.05$ was considered as indicative of a statistically significant difference.

\section{Role of the funding source}

This study received no funding. The corresponding author had full access to all the data in the study and had final responsibility for the decision to submit for publication. However, as a $\mathrm{PhD}$ candidate, the corresponding author is receiving a scholarship from UcLouvain.

\section{Results \\ Study selection and characteristics}

Following the bibliographical search, 1,961 studies were identified. After removal of duplicates, screening of titles and abstracts 245 studies were eligible and their full text assessed for final inclusion. Finally, 22 studies were retained contributing for 24 prevalence data (Additional file 1: Figure S1).

Nineteen (86.4\%) studies were cross-sectional, while three $(13.6 \%)$ were cross-sectional analysis of cohort studies. Studies were published between 1992 and 2015 and data collected between 1989 and 2013. Nineteen (86.4\%) studies were conducted in Africa (all from subSaharan Africa), and the remaining three (13.6\%) in Americas (Colombia, Peru), and South-East Asia (Indonesia). All countries outside Africa where in the control phase of malaria elimination, while those on the African continent were in endemic areas. Data collection and analysis was prospective in all studies except one. The most commonly used malaria diagnostic method was microscopy $(95.4 \%, n=21)$. The proportion of males varied between $46.2 \%$ and $63.7 \%$ as reported in eight studies. As reported in nine studies, the proportion of pregnant women who took intermittent preventive treatment for malaria (at least one dose) varied between $14.3 \%$ and $100 \%$. Furthermore, the proportion of pregnant women with malaria during pregnancy varied from $9.6 \%$ to $57.1 \%$ as reported in four studies (Additional file 1: Table S2).

Most of studies used a representative sample size of the targeted population (81.8\%), a probabilistic sampling (63.6\%), and described the city where the study was conducted $(95.4 \%)$. Precision (sample size $<385)$ was low in most studies (68.2\%) (Additional files 1: Tables S3 and S4).

\section{Prevalence of congenital and neonatal malaria in Africa and outside Africa}

Concerning clinical congenital malaria, only microscopy was used as diagnostic method. The overall prevalence was $40.4 \%$ (95\%CI $19.6-67.7 ; 17$ studies) with substantial heterogeneity (Fig. 1). The adjusted prevalence taking into account the variance due to difference in region/ country (hierarchical model) was $33.7 \%$ (95\% CI 6.977.2). The explained heterogeneity in this adjusted analysis was $0 \%$ for region and $98.9 \%$ for countries. There was no difference between the prevalence in Africa 39.5\% (95\%CI 17.2-59.5; 15 studies) and outside Africa 56.3\%o (95\%CI 0.0-406.1), $p=0.867$ (Fig. 1). 


\begin{tabular}{|c|c|c|c|c|c|c|c|c|c|c|}
\hline Author, Year & Cases & Sample & & & & & & Prevalence (per 1000) & [95\% C.I.] & Weight \\
\hline \multicolumn{11}{|l|}{ Africa } \\
\hline Akindele, 1993 - Microscopy & 4 & 59 & & & & & & 67.8 & {$[18.8 ; 164.6]$} & $4.9 \%$ \\
\hline Balaka, 2000 - Microscopy & 40 & 475 & & $\rightarrow$ & & & & 84.2 & {$[60.8 ; 112.9]$} & $6.2 \%$ \\
\hline Chiabi, 2012 - Microscopy & 21 & 227 & & $\longrightarrow$ & & & & 92.5 & {$[58.2 ; 137.9]$} & $5.9 \%$ \\
\hline Ekanem, 2008 - Microscopy & 71 & 546 & & $\longrightarrow$ & & & & 130.0 & {$[103.0 ; 161.2]$} & $6.2 \%$ \\
\hline Enweronu-Laryea, 2013 - Microscopy & 9 & 405 & & & & & & 22.2 & {$[10.2 ; 41.8]$} & $6.1 \%$ \\
\hline Falade, 2007 - Microscopy & 95 & 1875 & & + & & & & 50.7 & {$[41.2 ; 61.6]$} & $6.3 \%$ \\
\hline Lesi, 2010 - Microscopy & 14 & 100 & & & & & & 140.0 & {$[78.7 ; 223.7]$} & $5.4 \%$ \\
\hline Mwaniki, 2010 - Microscopy & 1 & 3187 & 18 & & & & & 0.3 & {$[0.0 ; 1.7]$} & $6.4 \%$ \\
\hline Nyirjesy, 1993 - Microscopy & 6 & 297 & + & & & & & 20.2 & {$[7.4 ; 43.5]$} & $6.0 \%$ \\
\hline Obiajunwa, 2005 - Microscopy & 2 & 120 & + & & & & & 16.7 & [ $2.0 ; 58.9]$ & $5.6 \%$ \\
\hline Obu, 2011 - Microscopy & 5 & 55 & & & & & & 90.9 & {$[30.2 ; 199.5]$} & $4.9 \%$ \\
\hline Omalu, 2012 - Microscopy & 0 & 152 & $\vdash$ & & & & & 0.0 & {$[0.0 ; 24.0]$} & $5.7 \%$ \\
\hline Orogade, 2004 - Microscopy & 17 & 206 & & $\longrightarrow$ & & & & 82.5 & {$[48.8 ; 128.8]$} & $5.9 \%$ \\
\hline Orogade, 2008 - Microscopy & 37 & 1875 & + & & & & & 19.7 & {$[13.9 ; 27.1]$} & $6.3 \%$ \\
\hline Ouédraogo, 2012 - Microscopy & 0 & 1309 & I: & & & & & 0.0 & {$[0.0 ; 2.8]$} & $6.3 \%$ \\
\hline Subgroup prevalence & & 10888 & & & & & & 39.5 & {$[17.2 ; 69.5]$} & $88.2 \%$ \\
\hline \multicolumn{11}{|l|}{ Heterogeneity: $I^{2}=97.5 \%, p<0.0001$} \\
\hline \multicolumn{11}{|l|}{ Outside Africa } \\
\hline Fitri, 2014 - Microscopy & 19 & 92 & & & & & & 206.5 & {$[129.2 ; 303.6]$} & $5.4 \%$ \\
\hline Silva, 2015 - Microscopy & 5 & 14017 & III & & & & & 0.4 & {$[0.1 ; 0.8]$} & $6.4 \%$ \\
\hline Subgroup prevalence & & 14109 & & & & & & 56.3 & {$[0.0 ; 406.1]$} & $11.8 \%$ \\
\hline \multicolumn{11}{|l|}{ Heterogeneity: $I^{2}=98.7 \%, p<0.0001$} \\
\hline Overall prevalence & & 24997 & & & & & & 40.4 & {$[19.6 ; 67.7]$} & $100.0 \%$ \\
\hline Heterogeneity: $I^{2}=98.3 \%, p<0.0001$ & & & & 1 & 1 & 1 & & & & \\
\hline \multicolumn{3}{|c|}{ Residual heterogeneity: $I^{2}=97.7 \%, p<0.0001$} & 0 & 100 & 200 & 300 & 400 & & & \\
\hline Test for subgroup differences: $\chi_{1}^{2}=0.03, \mathrm{df}$ & $\mathrm{f}=1(p=$ & $0.8668)$ & & & & & & & & \\
\hline
\end{tabular}

Concerning clinical neonatal malaria, the overall prevalence was $12.0 \%$ (95\%CI $1.4-30.3$; 12 studies) with substantial heterogeneity (Figs. 2 and 3). The adjusted prevalence taking into account the variance due to diagnostic methods and the variance due to difference in region/country (hierarchical model) was 12.9\%o (95\%CI: 0.1-39.7). The explained heterogeneity in this adjusted analysis was $0 \%$ for region, $0 \%$ for diagnostic method, $89.3 \%$ for countries, and $5.8 \%$ for diagnostic method. The prevalence was 9.1\% (95\% CI 0.8-23.6; 8 studies), 3.0\% (95\%CI 0.0-22.8; 2 studies), and $35.6 \%$ (95\%CI $0.0-238.5 ; 2$ studies) with microscopy, antigen technique, and molecular technique respectively; with no significant difference $(p=0.615)$ (Fig. 2). There was no difference between the prevalence in Africa $12.1 \%$ (95\%CI 1.3-31.2; 11 studies) and outside Africa 12.5\% (95\%CI 0.0-52.9), $p=0.802$ (Fig. 3).

The funnel plot (Additional file 1: Fig. S2) for congenital malaria studies suggested asymmetry confirmed by the Egger test $(p=0.001)$. This was not the case for neonatal malaria where there was some symmetry in the funnel plot (Egger test $p=0.1004$ ) (Additional file 1: Fig. S3).

\section{Discussion}

This first systematic review with meta-analysis of 28,083 neonates living in 14 endemic malaria countries points out a high prevalence of clinical congenital and neonatal malaria, with a substantial heterogeneity not explained by the geographical location of the study endemic area and diagnostic method used. Considering 1,000 neonates, 40 may experience malaria clinical disease during the first 7 days of their life. After this period, for those aged less than 28 days, among 1000 neonates, 10 may experience malaria clinical disease.

As suggested by several observational studies, the prevalence of neonatal malaria appears to be lower than that observed in adults and children under 5 years of 


\begin{tabular}{|c|c|c|c|c|c|c|c|c|c|c|}
\hline Author, Year & Cases S & Sample & & & & & & Prevalence (Per 1000) & [95\% C.I.] & Weight \\
\hline \multicolumn{11}{|l|}{ Antigen } \\
\hline Dicko-Traoré, 2011 & 3 & 267 & $\dot{i}$ & & & & & 11.2 & {$[2.3 ; 32.5]$} & $8.4 \%$ \\
\hline Enweronu-Laryea, 2013 & 0 & 522 & $\vdash$ & & & & & 0.0 & {$[0.0 ; 7.0]$} & $8.8 \%$ \\
\hline Subgroup prevalence & & 789 & $\stackrel{\vdots}{?}$ & & & & & 3.0 & {$[0.0 ; 22.8]$} & $17.2 \%$ \\
\hline \multicolumn{11}{|c|}{ Heterogeneity: $I^{2}=83.4 \%, p<0.0001$} \\
\hline \multicolumn{11}{|l|}{ Microscopy } \\
\hline Adja, 2009 & 5 & 615 & : & & & & & 8.1 & {$[2.6 ; 18.9]$} & $8.8 \%$ \\
\hline Dicko-Traoré, 2011 & 0 & 267 & $\stackrel{\vdots}{\vdots}$ & & & & & 0.0 & {$[0.0 ; 13.7]$} & $8.4 \%$ \\
\hline Enweronu-Laryea, 2013 & 0 & 522 & $\vdash \vdots$ & & & & & 0.0 & {$[0.0 ; 7.0]$} & $8.8 \%$ \\
\hline Ibhanesebhor, 1992 & 6 & 387 & $\vdots$ & & & & & 15.5 & {$[5.7 ; 33.4]$} & $8.6 \%$ \\
\hline Kitua, 1996 & 1 & 84 & $i$ & & & & & 11.9 & {$[0.3 ; 64.6]$} & $7.2 \%$ \\
\hline Mwaniki, 2010 & 4 & 4790 & tit & & & & & 0.8 & {$[0.2 ; 2.1]$} & $9.1 \%$ \\
\hline Obu, 2011 & 14 & 105 & & & & & & 133.3 & {$[74.9 ; 213.6]$} & $7.5 \%$ \\
\hline Pieros-Jiménez, 2011 & 1 & 80 & $i$ & & & & & 12.5 & [ $0.3 ; 67.7]$ & $7.1 \%$ \\
\hline Subgroup prevalence & & 6850 & $\dot{p}$ & & & & & 9.1 & {$[0.8 ; 23.6]$} & $65.6 \%$ \\
\hline \multicolumn{11}{|c|}{ Heterogeneity: $I^{2}=90.6 \%, p<0.0001$} \\
\hline \multicolumn{11}{|l|}{ Molecular } \\
\hline Dicko-Traoré, 2011 & 0 & 267 & $\longmapsto$ & & & & & 0.0 & {$[0.0 ; 13.7]$} & $8.4 \%$ \\
\hline Enweronu-Laryea, 2013 & 56 & 467 & & & $\longrightarrow$ & - & & 119.9 & {$[91.9 ; 152.9]$} & $8.7 \%$ \\
\hline Subgroup prevalence & & 734 & $\div$ & & & & & 35.6 & {$[0.0 ; 238.5]$} & $17.2 \%$ \\
\hline \multicolumn{11}{|c|}{ Heterogeneity: $I^{2}=98.6 \%, p=0.0140$} \\
\hline Overall prevalence & & 8373 & $<$ & & & & & 12.0 & {$[1.4 ; 30.3]$} & $100.0 \%$ \\
\hline \multicolumn{3}{|c|}{ Heterogeneity: $I^{2}=95.5 \%, p<0.0001$} & $\Gamma$ & 1 & T & 1 & $\neg$ & & & \\
\hline \multicolumn{3}{|c|}{ Residual heterogeneity: $I^{2}=94.1 \%, p<0.0001$} & 0 & 50 & 100 & 150 & 200 & & & \\
\hline \multicolumn{11}{|c|}{ Test for subgroup differences: $\chi_{2}^{2}=0.97, \mathrm{df}=2(p=0.6152)$} \\
\hline
\end{tabular}

age. Indeed, according to WHO, $11.5 \%$ to $46.4 \%$ of the cases were thought to occur in the under 5 age group in sub-Saharan Africa [1]. The relatively low prevalence of clinical malaria in the neonatal period is probably multifactorial $[36,37]$. The presence in the neonatal red blood cell of a high concentration of foetal haemoglobin that induces inadequate intraerythrocytic conditions for Plasmodium growth is considered one of the most plausible explanations [37-39]. The passively acquired neonatal immunity due to in utero transmission from the mother to the newborn could also play a role in its ability to not develop symptomatic forms of malaria even after exposure to Plasmodium [38]. As the kinetics of these passively acquired maternal antibodies show a progressive decline after three to six months, and that the amount of fetal haemoglobin decreases significantly at that age, children older than 6 months are more vulnerable to malaria
[39-41]. This may explain why the prevalence of malaria increases in infants after the neonatal period [40, 41].

Although based on the analysis of two studies done outside Africa against sixteen done on this continent, findings of the current review suggest a lower prevalence of clinical congenital malaria in sub-Saharan Africa compared to regions outside the continent. Given the small number of studies conducted outside Africa, it is necessary to have more studies done on the occurrence of clinical congenital and neonatal malaria in endemic regions outside Africa in order to draw meaningful conclusions. Nevertheless, if these results are confirmed on a larger sample, they could be explained by the fact that in Africa, the prevalence of gestational and placental malaria is higher than elsewhere in the world, as reported by Desai and colleagues, who found that one out of four women in this region presents evidence of placental malaria infection during childbirth [42]. Similar results were 


\begin{tabular}{|c|c|c|c|c|c|c|c|c|c|c|}
\hline Author, Year & Cases & Sample & & & & & & Prevalence (Per 1000) & [95\% C.I.] & Weight \\
\hline \multicolumn{11}{|l|}{ Africa } \\
\hline Antigen - Dicko-Traoré, 2011 & 3 & 267 & + & & & & & 11.2 & {$[2.3 ; 32.5]$} & $8.4 \%$ \\
\hline Antigen - Enweronu-Laryea, 2013 & 0 & 522 & $\vdash$ & & & & & 0.0 & {$[0.0 ; 7.0]$} & $8.8 \%$ \\
\hline Microscopy - Adja, 2009 & 5 & 615 & : & & & & & 8.1 & {$[2.6 ; 18.9]$} & $8.8 \%$ \\
\hline Microscopy - Dicko-Traoré, 2011 & 0 & 267 & $\stackrel{\vdots}{\vdots}$ & & & & & 0.0 & {$[0.0 ; 13.7]$} & $8.4 \%$ \\
\hline Microscopy - Enweronu-Laryea, 2013 & 0 & 522 & $\vdash$ & & & & & 0.0 & {$[0.0 ; 7.0]$} & $8.8 \%$ \\
\hline Microscopy - Ibhanesebhor, 1992 & 6 & 387 & $\vdots$ & & & & & 15.5 & {$[5.7 ; 33.4]$} & $8.6 \%$ \\
\hline Microscopy - Kitua, 1996 & 1 & 84 & $i$ & & & & & 11.9 & {$[0.3 ; 64.6]$} & $7.2 \%$ \\
\hline Microscopy - Mwaniki, 2010 & 4 & 4790 & 10: & & & & & 0.8 & {$[0.2 ; 2.1]$} & $9.1 \%$ \\
\hline Microscopy - Obu, 2011 & 14 & 105 & & & & & & 133.3 & {$[74.9 ; 213.6]$} & $7.5 \%$ \\
\hline Molecular - Dicko-Traoré, 2011 & 0 & 267 & 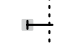 & & & & & 0.0 & {$[0.0 ; 13.7]$} & $8.4 \%$ \\
\hline Molecular - Enweronu-Laryea, 2013 & 56 & 467 & & & $\longrightarrow$ & - & & 119.9 & {$[91.9 ; 152.9]$} & $8.7 \%$ \\
\hline Subgroup prevalence & & 8293 & $\dot{\phi}$ & & & & & 12.1 & {$[1.3 ; 31.2]$} & $92.9 \%$ \\
\hline \multicolumn{11}{|l|}{ Heterogeneity: $I^{2}=95.9 \%, p<0.0001$} \\
\hline \multicolumn{11}{|l|}{ Outside Africa } \\
\hline Microscopy - Pieros-Jiménez, 2011 & 1 & 80 & $i$ & & & & & 12.5 & {$[0.3 ; 67.7]$} & $7.1 \%$ \\
\hline Subgroup prevalence & & 80 & $\stackrel{\vdots}{i}$ & - & & & & 12.5 & {$[0.0 ; 52.9]$} & $7.1 \%$ \\
\hline \multicolumn{11}{|l|}{ Heterogeneity: not applicable } \\
\hline Overall prevalence & & 8373 & $\dot{\alpha}$ & & & & & 12.0 & {$[1.4 ; 30.3]$} & $100.0 \%$ \\
\hline Heterogeneity: $I^{2}=95.5 \%, p<0.0001$ & & & $\Gamma$ & 1 & 1 & 1 & $\longrightarrow$ & & & \\
\hline \multicolumn{3}{|l|}{ Residual heterogeneity: $I^{2}=95.9 \%, p<0.0001$} & 0 & 50 & 100 & 150 & 200 & & & \\
\hline \multicolumn{11}{|c|}{ Test for subgroup differences: $\chi_{1}^{2}=0.06, \mathrm{df}=1(p=0.8019)$} \\
\hline
\end{tabular}

also reported by the WHO in 2019, which estimated that $29 \%$ of pregnant women living in areas of high to moderate transmission in sub-Saharan Africa were exposed to malaria [1]. This triggers the synthesis and transfer of maternal antibodies against Plasmodium from mother to fetus during pregnancy and confers passive immunity against malaria to the neonates in this area, compared to other regions of the world where pregnant women are less exposed to malaria [42]. More importantly, a correlation has been shown between maternal and fetal antibody levels [36]. In addition, some studies have shown a higher prevalence of malaria parasitaemia in neonates in sub-Saharan Africa, compared to those living outside the region [24, 43-48]. They estimated the prevalence of congenital malaria, regardless of the presence of symptoms, to be between $10.8 \%$ and $54.2 \%$ in sub-Saharan Africa, $12.5 \%$ and $18.5 \%$ in the province with the highest burden in China [43, 47, 48]. In the USA, between 1960 and 2005, only 60 cases of congenital malaria were observed, and only a few number of cases were reported in Latin America [49-51]. The clinical picture of neonatal malaria is therefore influenced by the level of endemicity in the country. Children born from mothers living in high endemic areas, and hence passively received antibodies during pregnancy, are less likely to present clinical symptoms of malaria compared to those born from mothers living in non-endemic areas. In the latter, malaria may mimic a neonatal sepsis and represents a life-threatening condition.

Unsurprisingly, most of the studies included in this review are from sub-Saharan Africa, as in many previous reviews on gestational or congenital malaria $[42,43]$. This is mainly due to the fact that $85 \%$ of the global burden of malaria is carried by nineteen sub-Saharan African countries and India, [1] possibly explaining their inclination to produce epidemiological data on clinical malaria in different age categories, including neonates.

In all the studies included in the current review, the diagnosis of malaria was made when the clinical picture was suggestive of infection and Plasmodium was the only infectious agent found in the biological exams. In lowincome settings, given the presence of many other parasitic, bacterial and viral life-threatening infections, it is sometimes challenging to incriminate Plasmodium as the main aetiology of an infectious state when other germs are found in the blood especially in neonates. Therefore, to avoid pejorative outcomes, it may be necessary to 
adjunct anti-malarial therapy to medications meant to cater for other associated infectious agents.

In the current study, malaria prevalence data were pooled regardless of Plasmodium species. This is because only two studies reported the presence of nonPlasmodium falciparum malaria. The low number of studies reporting on non-P. falciparum malaria was probably due to the fact that most of our studies were from sub-Saharan Africa, where P. falciparum is the main aetiology of malaria and is more often associated with clinical manifestations, whereas in America and South-East Asia, Plasmodium vivax and Plasmodium ovale are more prevalent and less likely to produce severe clinical forms compared to P. falciparum.

The results of the current study support the need to consider malaria as a plausible differential diagnosis of fever in neonates, in areas where malaria is still endemic in general, and in sub-Saharan Africa in particular. They also call for the intensification of actions geared towards preventing neonatal malaria by reinforcing therapeutic and preventive measures for pregnant women, and lastly, for the elaboration of specific guidelines for the treatment of malaria in neonates.

Nevertheless, the results of this review must be interpreted in the context of some limitations. Firstly, not all of the included studies reported the proportion of women who experienced malaria during pregnancy and the proportion, who received intermittent preventive treatment. This made it difficult to assess the influence of malaria in pregnancy on the prevalence of clinical congenital and neonatal malaria. Secondly, only three of the studies included in the analysis were conducted outside sub-Saharan Africa, making it difficult to generalize the results to all malaria endemic areas. Thirdly, only two studies reported the presence of $P$. vivax in their sample, thus a subgroup analysis according to Plasmodium species was not conducted. Nevertheless, this study is the first to comprehensively synthesize epidemiological data on clinical congenital and neonatal malaria in endemic areas. Strong and robust methodological methods were used to minimize bias and produce the most accurate estimates. In addition, no restriction related to language or year of publication were applied, which allowed the analysis of all potentially eligible studies.

\section{Conclusion}

Clinical malaria in neonatal period is not a rare event especially in endemic settings. There is a need to intensify efforts aimed at preventing neonatal malaria, by strengthening therapeutic and preventive measures for pregnant women, and to develop specific guidelines for the treatment of malaria during the neonatal period.

\section{Supplementary information}

Supplementary information accompanies this paper at https://doi. org/10.1186/s12936-020-03373-8.

Additional file 1: Figures and Tables

\section{Authors' contributions}

$C D$ and $A R$ conceived the idea of the study and developed the protocol. CD and JJB did the literature search. CD and RNN selected the studies. CD and RNN extracted the relevant information. CD and JJB synthesized the data. CD wrote the first draft of the paper. $C D, J J B, R N N$, and AR critically revised successive drafts of the paper and approved the final version. AR supervised the overall work. CD and AR are the guarantors of the review. All authors read and approved the final manuscript.

Funding

None.

Availability of data and materials

All related materials are available in the appendix.

Ethics approval and consent to participate

Not applicable.

\section{Consent for publication}

All authors approved the final version of the manuscript and agree for publication.

\section{Competing interests}

We declare no competing interests.

\section{Author details}

${ }^{1}$ Epidemiology and Biostatistics Unit, Institut de Recherche Expérimentale et Clinique, Université catholique de Louvain, Brussels, Belgium. ${ }^{2}$ Department of Epidemiology and Public Health, Centre Pasteur of Cameroon, Yaoundé, Cameroon. ${ }^{3}$ School of Public Health, University of Buea, Buea, Cameroon.

Received: 21 May 2020 Accepted: 12 August 2020

Published online: 28 August 2020

\section{References}

1. WHO. World malaria report 2019 [Internet]. Geneva, World Health Organization, 2019 [cited 2020 Jan 31]. https://www.who.int/publications-detai I/world-malaria-report-2019.

2. Weiss DJ, Lucas TCD, Nguyen M, Nandi AK, Bisanzio D, Battle KE, et al. Mapping the global prevalence, incidence, and mortality of Plasmodium falciparum, 2000-17: a spatial and temporal modelling study. Lancet. 2019;394:322-31.

3. Dhiman S. Are malaria elimination efforts on right track? An analysis of gains achieved and challenges ahead. Infect Dis Poverty. 2019;8:14.

4. Gething PW, Casey DC, Weiss DJ, Bisanzio D, Bhatt S, Cameron E, et al. Mapping Plasmodium falciparum mortality in Africa between 1990 and 2015. N Engl J Med. 2016;375:2435-45.

5. Battle KE, Lucas TCD, Nguyen M, Howes RE, Nandi AK, Twohig KA, et al. Mapping the global endemicity and clinical burden of Plasmodium vivax, 2000-17: a spatial and temporal modelling study. Lancet. 2019;394:332-43.

6. Carter KH, Singh P, Mujica OJ, Escalada RP, Ade MP, Castellanos LG, et al. Malaria in the Americas: trends from 1959 to 2011. Am J Trop Med Hyg. 2015;92:302-16. 
7. Feleke DG, Gebretsadik D, Gebreweld A. Analysis of the trend of malaria prevalence in Ataye, North Shoa, Ethiopia between 2013 and 2017. Malar J. 2018;17(1):323.

8. Gautam N, Kakchapati S, Shrestha S, Wanishsakpong W. Patterns and trends of malaria in 25 risk districts of Nepal from 2001 to 2017. Clin Exp Vaccine Res. 2019;8:77.

9. Karema C, Aregawi MW, Rukundo A, Kabayiza A, Mulindahabi M, Fall IS, et al. Trends in malaria cases, hospital admissions and deaths following scale-up of anti-malarial interventions, 2000-2010. Rwanda. Malar J. 2012;11:236.

10. Hiwat H, Martínez-López B, Cairo H, Hardjopawiro L, Boerleider A, Duarte EC, et al. Malaria epidemiology in Suriname from 2000 to 2016: trends, opportunities and challenges for elimination. Malar J. 2018;17:418.

11. WHO. Countries and territories certified malaria-free by WHO [Internet]. Geneva, World Health Organization. [cited 2020 Feb 16]. http://www.who. int/malaria/areas/elimination/malaria-free-countries/en/.

12. Griffin JT, Ferguson NM, Ghani AC. Estimates of the changing age-burden of Plasmodium falciparum malaria disease in sub-Saharan Africa. Nat Commun. 2014;5:3136.

13. Randall LM, Kenangalem E, Lampah DA, Tjitra E, Mwaikambo ED, Handojo T, et al. Age-related susceptibility to severe malaria associated with galectin-2 in highland Papuans. J Infect Dis. 2010;202:117-24.

14. Dondorp AM, Lee SJ, Faiz MA, Mishra S, Price R, Tjitra E, et al. The relationship between age and the manifestations of and mortality associated with severe malaria. Clin Infect Dis. 2008:47:151-7.

15. D'Alessandro U, Ubben D, Hamed K, Ceesay SJ, Okebe J, Taal M, et al. Malaria in infants aged less than six months-is it an area of unmet medical need? Malar J. 2012;11:400.

16. WHO. High-risk groups [Internet]. Geneva, World Health Organization. [cited 2020 Feb 16]. Available from: http://www.who.int/malaria/areas/ high_risk_groups/en/.

17. Williams K, Thomson D, Seto I, Contopoulos-loannidis DG, loannidis JPA, Curtis S, et al. Standard 6: age Groups for Pediatric Trials. Pediatrics. 2012;129(Supplement 3):S153-60.

18. Carneiro I, Roca-Feltrer A, Griffin JT, Smith L, Tanner M, Schellenberg JA, et al. Age-patterns of malaria vary with severity, transmission intensity and seasonality in sub-Saharan Africa: a systematic review and pooled analysis. PLoS ONE. 2010;5:e8988.

19. Ekanem AD, Anah MU, Udo JJ. The prevalence of congenital malaria among neonates with suspected sepsis in Calabar, Nigeria. Trop Doct. 2008;38:73-6.

20. Obu H, Ibe B. Neonatal malaria in the gambia. Ann Med Health Sci Res. 2011;1:45-54

21. Olupot-Olupot P, Eregu EIE, Naizuli K, Ikiror J, Acom L, Burgoine K. Neonatal and congenital malaria: a case series in malaria endemic eastern Uganda. Malar J. 2018;17:171.

22. Akindele JA, Sowunmi A, Abohweyere AEJ. Congenital malaria in a hyperendemic area: a preliminary study. Ann Trop Paed. 1993;13:273-6.

23. Olowu JA, Sowumni A, Abohweyere AE. Congenital malaria in a hyperendemic area: a revisit. Afr J Med Med Sci. 2000;29:211-3.

24. Larkin GL, Thuma PE. Congenital mlaria in a hyperendemic area. Am J Trop Med Hyg. 1991;45:587-92.

25. Menendez C, Mayor A. Congenital malaria: the least known consequence of malaria in pregnancy. Semin Fetal Neonatal Med. 2007;12:207-13.

26. Stroup DF, Berlin JA, Morton SC, Olkin I, Williamson GD, Rennie D, et al. Meta-analysis of observational studies in epidemiology: a proposal for reporting. JAMA. 2000;283:2008-12.

27. Falade C, Mokuolu O, Okafor H, Orogade A, Falade A, Adedoyin O, et al. Epidemiology of congenital malaria in Nigeria: a multi-centre study. Trop Med Int Health. 2007;12:1279-87.

28. Mukhtar M. The growing incidence of neonatal malaria-a situational review in developing countries. Niger J Med. 2007;16:25-30.

29. Stassijns J, van den Boogaard W, Pannus P, Nkunzimana A, Rosanas-Urgell A. Prevalence and diagnostics of congenital malaria in rural Burundi, a cross-sectional study. Malar J. 2016;15:443.
30. Ibhanesebhor SE. Clinical characteristics of neonatal malaria. J Trop Pediatr. 1995:41:330-3.

31. EBP. Critical Appraisal Tools [Internet]. Joanna Briggs Institute [cited 2020 Feb 11]. https://joannabriggs.org/ebp/critical_appraisal_tools.

32. Barendregt JJ, Doi SA, Lee YY, Norman RE, Vos T. Meta-analysis of prevalence. J Epidemiol Community Health. 2013;67:974-8.

33. Cochran WG. The combination of estimates from different experiments. Biometrics. 1954;10:101-29.

34. Huedo-Medina TB, Sánchez-Meca J, Marín-Martínez F, Botella J. Assessing heterogeneity in meta-analysis: q statistic or 12 index? Psychol Methods. 2006;11:193-206.

35. Egger M, Davey Smith G, Schneider M, Minder C. Bias in meta-analysis detected by a simple, graphical test. BMJ. 1997:315:629-34.

36. Riley EM, Wagner GE, Akanmori BD, Koram KA. Do maternally acquired antibodies protect infants from malaria infection? Parasite Immunol. 2001;23:51-9.

37. Riley EM, Wagner GE, Ofori MF, Wheeler JG, Akanmori BD, Tetteh K, et al. Lack of association between maternal antibody and protection of African infants from malaria infection. Infect Immun. 2000;68:5856-63.

38. Congenital malaria. N Engl J Med. 1997;336:71-2.

39. Billig EM, McQueen PG, McKenzie FE. Foetal haemoglobin and the dynamics of paediatric malaria. Malar J. 2012;11:396.

40. McGuinness D, Koram K, Bennett S, Wagner G, Nkrumah F, Riley E. Clinical case definitions for malaria: clinical malaria associated with very low parasite densities in African infants. Trans R Soc Trop Med Hyg. 1998;92:527-31.

41. Snow RW, Nahlen B, Palmer A, Donnelly CA, Gupta S, Marsh K. Risk of severe malaria among African infants: direct evidence of clinical protection during early infancy. J Infect Dis. 1998;177:819-22.

42. Desai M, ter Kuile FO, Nosten F, McGready R, Asamoa K, Brabin B, et al. Epidemiology and burden of malaria in pregnancy. Lancet Infect Dis. 2007;7:93-104

43. Uneke CJ. Congenital malaria: an overview. Tanzania J Health Res. 2011;13:264-80.

44. Enweronu-Laryea CC, Adjei GO, Mensah B, Duah N, Quashie NB. Prevalence of congenital malaria in high-risk Ghanaian newborns: a crosssectional study. Malar J. 2013;12:17.

45. Runsewe-Abiodun IT, Ogunfowora OB, Fetuga BM. Neonatal malaria in Nigeria -a 2 year review. BMC Pediatr. 2006;6:19.

46. Lehner PJ, Andrews CJ. Congenital malaria in Papua New Guinea. Trans R Soc Trop Med Hyg. 1988;82:822-6.

47. Nagaraj N, Berwal PK, Sharma M, Jevaji P, Swami S, Yadav V, et al. Congenital and neonatal malaria in Asian Indian population. Int J Commun Med Public Health. 2017;2:639-42.

48. Tao Z, Fang Q, Liu X, Culleton R, Tao L, Xia H, et al. Congenital malaria in China. PLoS Negl Trop Dis. 2014;8:e2622.

49. Lesko CR, Arguin PM, Newman RD. Congenital malaria in the United States: a review of cases from 1966 to 2005. Arch Pediatr Adolesc Med. 2007;161:1062-7.

50. Castellanos ME, Bardají A, Menegon M, Mayor A, Desai M, Severini C, et al. Plasmodium vivax congenital malaria in an area of very low endemicity in Guatemala: implications for clinical and epidemiological surveillance in a malaria elimination context. Malar J. 2012;11:411.

51. Carmona-Fonseca J, Maestre-B A. Incidencia de las malarias gestacional, congénita y placentaria en Urabá (Antioquia, Colombia), 2005-2007. Rev Colombiana Obstetr Ginecol. 2009;60:19-33.

\section{Publisher's Note}

Springer Nature remains neutral with regard to jurisdictional claims in published maps and institutional affiliations. 